\title{
An Electromyographic Study of the Abdominal Muscles of Tetraplegic Patients ${ }^{\star}$
}

\author{
J. M. Goldman, MB, BS, MRCP (UK), ${ }^{1}$ J. R. Silver, MB, BS, FRCP ED \& \\ Lond $^{2}$ and R. P. Lehr, PhD ${ }^{3}$ \\ ${ }^{1}$ Lung Function Unit, Brompton Hospital, Fulham Road, London, England. \\ ${ }^{2}$ National Spinal Injuries Centre, Stoke Mandeville Hospital, Aylesbury, Bucks., \\ England. ${ }^{3}$ Associate Professor of Anatomy, Southern Illinois University School of \\ Medicine, Southern Illinois University of Carbondale, Illinois, U.S.A.
}

\begin{abstract}
Summary
Bipolar fine wire electrodes were used to make electromyographic (EMG) recordings of the abdominal muscles of 8 stable complete tetraplegic patients. Synchronous recordings were made of ventilation, and in 5 subjects an oesophageal electrode was used to record diaphragm EMG. In all 8 subjects we demonstrated phasic inspiratory EMG activity which we have shown to be localised to the abdominal muscles. We believe that this activity was triggered by stretching of the abdominal wall on inspiration. Its effect will be to decrease abdominal wall compliance allowing the diaphragm to generate greater intra-abdominal pressure as it descends, thus promoting inflation of the lower rib cage.
\end{abstract}

Key words: Tetraplegic patients; Abdominal muscles; Electromyographic study

\section{Introduction}

Tetraplegic patients may have severe respiratory difficulties, they maintain ventilation predominantly with their diaphragms as their intercostal and abdominal muscles are paralysed. EMG activity in the intercostal muscles of tetraplegic patients is well described (Guttmann and Silver, 1966; De Troyer and Heilporn, 1980) and has been said to confer respiratory advantage (De Troyer and Heilporn, 1980). In 1966 Guttmann and Silver detected phasic inspiratory EMG activity in the abdominal muscles of stable patients with cervical cord injury. Silver and

\footnotetext{
^ Read at the Scientific Meeting of the International Medical Society of Paraplegia in Edinburgh, Scotland, September, 1985.

Correspondence to: Dr J. M. Goldman, Lung Function Unit, Brompton Hospital, Fulham Road, London, England, SW3 6HP.
} 
Lehr (1981) were unable to reproduce this finding. The presence of such EMG activity, associated with an increase in tone of the abdominal muscles, would decrease abdominal wall compliance and improve ventilation by increasing lower rib cage expansion (De Troyer, 1983). The aim of this study was to make qualitative recordings of the electrical activity of the abdominal muscles of tetraplegic patients.

\section{Patients and methods}

We studied 8 patients with functionally complete transection of the cervical spinal cord as evidenced by clinical examination (Table 1). All were at least 3

Table 1 Tetraplegic patients studied

\begin{tabular}{lccc}
\hline \multicolumn{1}{c}{ Name } & Sex & Age & Lesion \\
\hline DG & M & 21 & C5,6 \\
SF & M & 25 & C6 \\
JH & M & 21 & C5 \\
JW & F & 31 & C6 \\
WB & M & 24 & C5 \\
HB & M & 34 & C6 \\
MC & M & 33 & C5,6 \\
JG & F & 35 & C6 \\
\hline
\end{tabular}

months post-injury and none was suffering from any respiratory complication at the time of examination.

Bipolar fine wire electrodes were manufactured in the manner of Basmajian (1962) using $0.006 \mathrm{~cm}$ stainless steel wire, coated with Diamel (Johnston Mathey). The insulation was removed at one end baring a mm length which was fashioned into a hook to anchor the wire within muscle, $2 \mathrm{~cm}$ of wire was bared at the other end to connect to the amplification system. The wires were positioned in 27 gauge needles such that their tips would not touch and cause a short circuit. One pair of wires was inserted $3 \mathrm{~cm}$ to the left of the midline at the level of the umbilicus, into the rectus abdominis muscle. 3 sets of wires were inserted $3 \mathrm{~cm}$ medial to the left anterior axillary line at the level of the umbilicus to depths to coincide with external oblique, internal oblique and transversus abdominis muscles. The electrodes were within $0.5 \mathrm{~cm}$ of each other at the surface.

The wires were connected via springs to the pre-amplifiers of a Medelec MS6 module equipped with four AA6 amplifiers. EMG activity was displayed on an oscilloscope and recorded on photographic paper. 5 subjects consented to the introduction of oesophageal electrodes to record diaphragm EMG (Druz and Sharp, 1981). These were inserted via the nares to $45 \mathrm{~cm}$ and adjusted to provide maximum EMG amplitude. Ventilation was monitored using a conical pneumotachograph accurate to $300 \mathrm{~L} / \mathrm{min}$ and a Siemens EMT 32C differential pressure transducer. The signal was amplified and integrated, and then displayed as volume on the Medelec MS6 oscilloscope. This system was calibrated with a 1 litre syringe.

The position of the wires within muscle was first of all confirmed by voluntarily inducing spasms within the abdominal muscles, by drawing a finger firmly across the skin of the lower abdomen or upper thigh. Any wire which failed to detect 
$1 \mathrm{~L}]$

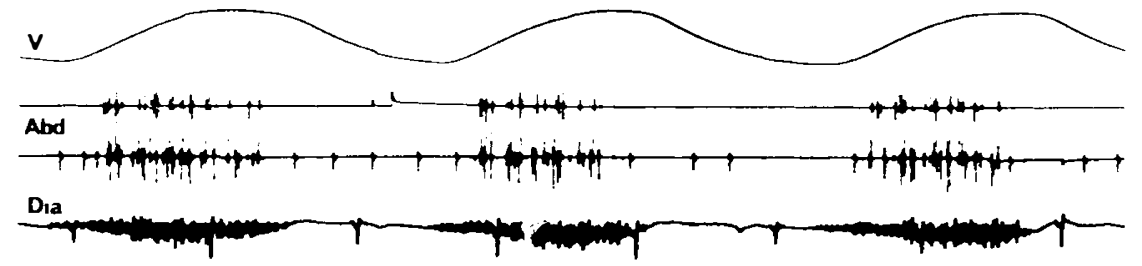

$1 \mathrm{sec}$

Figure 1. EMG recording of the Abdominal muscles (Abd), Diaphragm (Dia) and ventilation (V) of a C6 tetraplegic patient. Upward deflection of V represents inspiration. Note phasic inspiratory EMG activity of the abdominal muscles.

tonic EMG activity was discarded. Subjects breathed through a mouthpiece at tidal volume and then voluntarily increased their minute volume up to maximal hyperventilation whilst continuous EMG recordings were made. EMG activity during cough, strain and Valsalva manoeuvres was also recorded.

\section{Results}

Tonic EMG activity was detected in the abdominal muscles during induced spasm. This confirmed that each electrode was recording from muscle. In each patient at least 3 electrodes that were recording satisfactorily from muscle were available for use. In all 8 patients examined we detected phasic inspiratory activity of the abdominal muscles (Figure 1). This activity was not present during tidal breathing but became apparent as ventilation increased (Figure 2).

$1 \mathrm{~L}]$

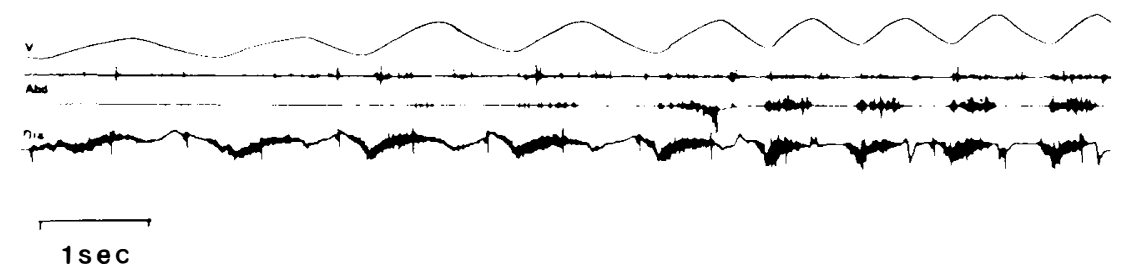

Figure 2. EMG recording of the Abdominal muscles (Abd), Diaphragm (Dia) and ventilation (V) of a C5 tetraplegic patient. Upward deflection of V represents inspiration. Note increasing amplitude of phasic inspiratory EMG activity of the abdominal muscles with increasing minute volume.

The amplitude of this EMG activity was found to increase with minute volume and in two subjects developed into tonic activity clinically associated with spasm of the abdominal muscles (Figure 3).

\section{Discussion}

There was good evidence that the phasic inspiratory EMG activity detected was derived from the abdominal muscles themselves and was not radiating through from the diaphragm. Firstly, the fine wire electrodes we employed will only detect electrical activity within $1.5 \mathrm{~mm}$ of their tips. Secondly, we were able to 
$1 \mathrm{~L}]$

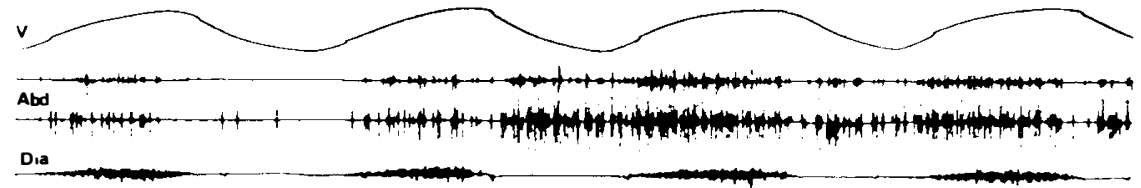

$1 \mathrm{sec}$

Figure 3. EMG recording of the Abdominal muscles (Abd), Diaphragm (Dia) and ventilation (V) of a C6 tetraplegic patient. Upward deflection of V represents inspiration. Note phasic inspiratory abdominal muscle activity develops into tonic activity which was clinically associated with abdominal muscle spasm.

demonstrate tonic EMG activity in the abdominal muscles whilst normal phasic inspiratory activity was present in the diaphragm (Figure 4); these two activities are quite different in timing and shape. Thirdly, on straining (which was an expulsive effort against a closed glottis) intense tonic activity was present in the diaphragm due to isometric contraction, whilst there was no EMG activity in the abdominal muscles (Figure 5). We have thus demonstrated high amplitude tonic EMG activity separately in the abdominal muscles and the diaphragm. We conclude that the phasic inspiratory EMG activity detected in the abdominal muscles arises locally.

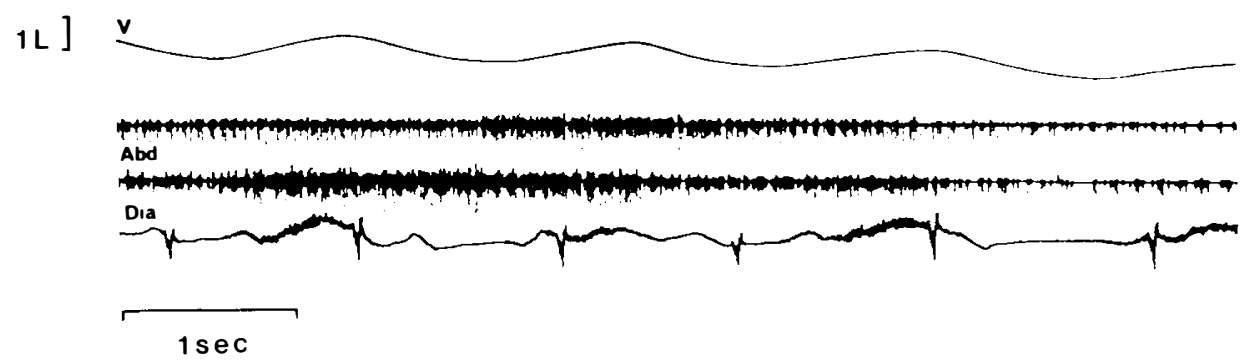

Figure 4. EMG recording of the Abdominal muscles (Abd), Diaphragm (Dia) and ventilation (V) of a C5 tetraplegic patient. Upward deflection of $\mathrm{V}$ represents inspiration. Note tonic activity present in the abdominal muscles with normal phasic inspiratory activity in the Diaphragm.

\section{Abd}

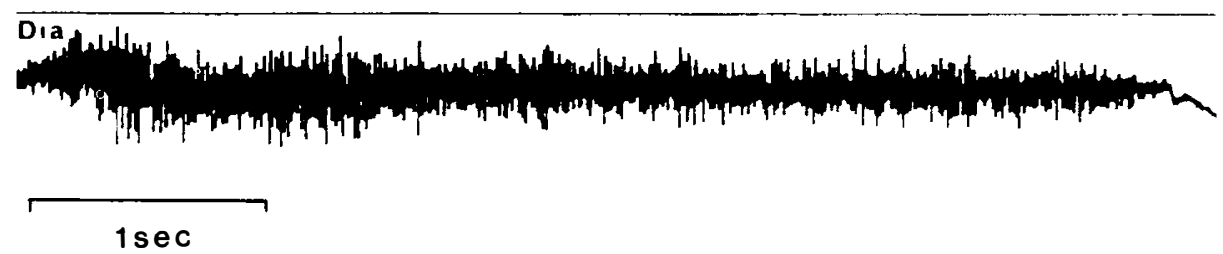

Figure 5. EMG recording of the Abdominal muscles (Abd) and Diaphragm (Dia). Note tonic activity in the diaphragm during straining with no activity in the abdominal muscle. 
The cause of the phenomenon we have described is uncertain but can be considered with reference to chest wall mechanics. The abdominal cavity can be considered as a closed bag of fluid. Its posterior and inferior boundaries are fixed by the spine and pelvis respectively, thus when the diaphragm descends on inspiration, its anterior boundary, i.e. the abdominal wall, is pushed outward (Agostoni and Mead, 1964) and the abdominal muscles are stretched. We believe that the EMG activity we have detected is due to a stretch reflex mediated at spinal level. The stimulus is stretching of the abdominal wall which activates abdominal muscle spindles and results in muscular contraction. In practice we have observed that the presence and amplitude of phasic inspiratory EMG activity relates to the degree and rate of abdominal wall distension. Some patients have noted that a rapid deep inspiration induces spasm within their abdominal muscles and we have demonstrated that this is initiated by the inspiratory EMG activity described (Figure 4). Phasic inspiratory EMG activity in the abdominal muscles during increased ventilation may have functional significance, as an increase in the tone of these muscles decreases abdominal wall compliance. Tetraplegic patients have greater abdominal wall compliance than normal subjects (Goldman et al., 1985), therefore on inspiration there is little resistance to descent of the diaphragm because the abdomen is easily distended, and the intra-abdominal pressure generated is less than normal. Intra-abdominal pressure works in two ways to inflate the lower rib cage. Firstly, by a direct effect on the area of apposition of rib cage to diaphragm (Mead, 1979) and secondly by acting as a fulcrum for the insertional forces of the diaphragm (De Troyer et al., 1982). If intra-abdominal pressure is diminished the lower rib cage is poorly expanded. Danon et al. (1978) and Mortola and Sant Ambrogio (1979) have demonstrated the excursions of the lower rib cage during respiration are decreased in tetraplegic patients and depending on posture may even be paradoxical. We suggest that in tetraplegic patients breathing at increased minute volumes, descent of the diaphragm stretches the abdominal muscles. This sets up a local reflex causing these muscles to contract. Abdominal wall compliance is reduced, resisting descent of the diaphragm and intra-abdominal pressure rises promoting lower rib cage expansion. It is possible that this reflex has a beneficial effect on ventilation.

\section{Acknowledgements}

We wish to thank Professor T. A. Sears, Sobell Department of Neurophysiology, Queen Square, for his advice and interest; Dr H. L. Frankel and Mr I. Nuseibeh for permission to study their patients; Lone Rose for her considerable assistance during the experimental work and Roy Robinson, Medical Electronics Department, Stoke Mandeville Hospital for building the integrating amplifier and technical advice.

Dr J. M. Goldman was supported by a Brompton Hospital Clinical Research Committee Grant.

\section{Résumé}

Electrodes de fil fin ont ete usage par faire enregistrement electromyographique (EMG) des muscles abdomenaux de huit (8) tetraplegique patients stables. Enregistrements synchronique ont ete pris de ventilation et dans cinq (5) sujets une electrode oesophageal ont ete usage pour enregistre EMG diaphragmatique. Dans tout les (8) sujets nous avons demonte activite EMG phasique d'inspiration que nous avons montre d'etre localise aux muscles abdomenaux. Nous croyons que cette activite a 
ete cause par l'etirate du mur abdominal avec inspiration. Son effet seront etre de decroitre la complaisance du mur abdomenal et al permettre la diaphragm a engendrer plus de pression intraabdomenal quand elle descend, ainsi promaivant inflation de cage thoracique inferieur.

\section{Zusammenfassung}

Von 8 stabilisierten tetrapralysierten Patienten wurden Elektromyographische Aufnahmen der Bauchmuskulatur gemacht. Dafbr wurden feine Drahtelektroden benutzt. Gleichzeitig wurden Aufnahmen der Atmungstatigkeit gemacht. Bei 5 Patienten wurde ein Diphragma EMG mit oesophagael Elektroden gemacht. Bei allen 8 Patienten wurden Einatmurgphasen bemerkt, die nach unseren Versuchen mit der Bauchmuskulatur zusammen hingen.

Es soll erzielt werden, walvend inspiratonschen Tiefstands des Zwerchfelles die Dehnbarkeit ein zuschrenken um grberen intraabdominalen Druck zu erzeugen. Dieses gelchient walvend der Lenkung des Zwerchfelles um dadurch die Aufblahung des unteren Brustkorbes zu fordern.

\section{References}

Agostoni E, Mead J 1964 Statistics of the respiratory system. In: Handbook of Physiology, Section 3: Respiration. Vol. 1. Eds: Fenn WO and Rahn H. The American Physiological Society. Washington. 387-409.

BASMAJIAN JV STECKo G 1962 A new bipolar electrode for electromyography. Journal of Applied Physiology 17:849.

DanON J, DruZ WS, Goldberg NB, et al. 1979 Function of the isolated paced diaphragm and the cervical accessory muscles in $\mathrm{C} 1$ quadriplegics. American Review of Respiratory Disease 119:909-919.

De Troyer A 1983 Mechanical action of the abdominal muscles. Bulletin Europeen de Physiopathologie Respiratoire 19:575-581.

De Troyer A, Heilporn A 1980 Respiratory mechanics in quadriplegia. The respiratory function of the intercostal muscles. American Review of Respiratory Disease 122:591-606.

De Troyer A, Sampson M, Sigrist S, Macklem PT 1982 Action of costal and crural parts of the diaphragm on the rib cage of dogs. Journal of Applied Physiology 53:30-39.

DRUZ SD, SHARP JT 1981 Activity of respiratory muscles in upright and recumbent humans. Journal of Applied Physiology 51:1552-1561.

Goldman JM, Morgan MDL, Denison DM 1985 Measurement of abdominal wall compliance. Thorax 40:701.

GutTMANN L, Silver JR 1965 Electromyographic studies on reflex activity of the intercostal and abdominal muscles in cervical cord lesions. Paraplegia 3:1-22.

MEAD J 1979 Functional significance of the area of apposition of diaphragm to rib cage. American Review of Respiratory Disease 119; 31-32.

Mortola JP, Sant Ambrogio G 1978 Motion of the rib cage and abdomen in tetraplegic patients. Clinical Science and Molecular Medicine 54:25-32.

SILVER JR, LEHR RP 1981 Electromyographic investigation of the diaphragm and intercostal muscles in tetraplegics. Journal of Neurology, Neurosurgery and Psychiatry 44:837-842. 